and its variouis organs must have hegemony and control, despite evidence that in Pakistan the outmoded functioning of the state is the problem that stifles the establishment of goodgovernance and credible and efficient institutions. Their position was that a better implementation, by "good" people, of prevailing procedures and systems will solve the problems.

\section{LeAdership Deficit}

The TF had recommended that the arena for reform should be the universities, and as a corollary the figure of the vice chancellor emerged as the linchpin for taking forward the reforms. However, the appointment of the vice chancellor is the prerogative of the chancellor, and amazingly there are no criteria for this appointment, nor is there any transparent process that could ensure merit. Consequently, we have many vice chancellors who are not the best leaders-many not having been academics to begin with. Nevertheless, appointment as a vice chancellor bestows considerable executive powers on the person, and she or he has a key role in the trajectory of institutional functioning. Unfortunately, most are averse to learning and change. Their decisions and actions are primarily informed by what they consider would please the higher-ups, the desire to retain their positions, and secondarily with professional or institutional requirements. Thus, the most critical positions of higher education management are occupied by individuals who may not be too suitable for the job, are inwardly anxious and insecure, and lack the necessary qualities to provide credible leadership. The rather whimsical methods of their appointment, and the conditions of service; their lack of vision, confidence in themselves; and low institutional or professional commitment—all combine to make a pessimistic mix for reform.

\section{CONCLUSION}

The reform effort in Pakistan was derailed because of two crucial weaknesses. First, the overall mode of state functioning, policymaking, and governance is top-down, nontransparent, and rigidly hierarchial. That mindset bedevils reform in higher education, in general, and the manner in which universities function, in particular. For example, the TF had recommended that to drive and facilitate the reform effort, an apex Higher Education Commission should be established, which was done in late 2002. However, the commission is functioning like any other Pakistani bureaucracy. Second, at the microlevel, the leadership of institutions of higher learning is extremely weak. As indicated above, the leaders remained largely opposed to reform, and concern for improvements in institutional functioning remains a low priority. Initially, the majority of vice chancellors felt obliged to go along with the flow, they kept making the right noises at the right times and places but bided their time and tried to do as little as absolutely necessary. As the fervor for change started waning, the beginning of which was around late 2002, the old attitudes were reasserted. Those for the status quo but adept at the game of position, reascended; and, in an ironic twist, those who championed reform were marginalized or ended up on the defensive: proving once again that in Pakistan the winning approach is doing the least, mouthing the right things, and staying the course of the status quo. The unfortunate upshot is that the reform process that was initiated with fanfare has largely come to naught and, some argue, has made the situation worse. The broader lesson that our case illustrates is that the determinants of the outcomes of such efforts are the commitment, honesty of purpose, and know-how of key actors; and the wider psychosocial and political context that shape and inform their decisions and actions.

\section{Recognition of Education for Refugees: The Norwegian Experience}

\section{MARIT EgNER}

Marit Egner is an adviser of the Norwegian Agency for Quality Assurance in Education (NOKUT). Address: NOKUT, P.O.Box 1708 Vika, N-0121 Oslo, Norway E-mail: Marit.Egner@nokut.no.

any refugees arrive in Europe with few, if any, education$\mathbf{Y}$ al documents. Often it is difficult to obtain verifications from their countries of origin. Some people exploit this situation by producing fraudulent documents, and this necessitates an alternative method that enables candidates with bona fide qualifications to demonstrate the authenticity of their qualifications. Today, I0०,000 refugees are settled in Norway, a country of only 4.5 million inhabitants, and about 15 percent of these refugees have some form of higher education.

In the Lisbon Convention, the issues relating to refugee credentials are covered by Article VII. The signatories are expected to put in place fair and expeditious systems for evaluation of qualifications for refugees with insufficient documentation.

In I999, a working group from the European Network of National Information Centers on Academic Recognition and Mobility (ENIC) suggested using a "background paper" for refugees, based on the applicants' own reconstructions of their educational backgrounds. In 2003, a Norwegian procedure for recognition of refugee qualifications was developed, mainly built on the ENIC recommendations and experiences with assessment of prior learning. There is, however, a difference between assessing documented informal prior learning and assessing undocumented, but formal, qualifications of refugees - the latter learning being a planned process, often within a known education system.

\section{The Norwegian Refugee Process}

The procedure has two phases. The first is to establish the applicant's educational portfolio by collecting supporting evidence and reconstructing his or her course descriptions. The 
second phase is an evaluation of the applicant's education, comparing it to the Norwegian higher education system through an evaluation interview. While the first phase may be guided by administrators, the second must engage academic staff at the higher education institutions.

\section{The Pilot Project}

In 2004, the Norwegian Agency for Quality Assurance in Education (NOKUT) carried out a pilot project, together with Oslo University College and Narvik University College, to assess the procedure. The project only admitted candidates with engineering degrees for the sake of coherence and comparability, and there were 20 candidates from Afghanistan, Iraq, Somalia, and the former Yugoslavia. Their dates of graduation spanned from 1977 to 2000. Six candidates were recruited from the northern part of Norway and i4 from the Oslo region. In the first phase the candidates were assisted either by NOKUT or by municipal refugee consultants, but in the second phase, all the candidates were called in for evaluation interviews at one of the two university colleges.

Four candidates received recognition of their degrees as equivalent to a three-year Norwegian bachelor's degree, I2 candidates received recognition as having one or two years of higher education, and four did not get any recognition of higher education. Where full recognition was not granted, the candidate received advice on further education possibilities.

There was no language requirement for participation, and in a few Afghan cases language problems were a barrier to an accurate positioning of the candidate's level in engineering. If future candidates wait until they have a good command of Norwegian or English, the validity of the evaluation interview will be enhanced and the candidates will have a smoother transition into further studies or professional employment. Another lesson gleaned from the project was that in order to decide the candidate's level of expertise it was important to involve academic staff with expert knowledge in the candidate's particular specialty.

The time span from the candidates' graduation to their initiation into the recognition project was up to 25 years. Some candidates had acquired new professional competence while others had never worked as engineers and lacked experience with recent technological developments.

One dilemma was that where a normal credential evaluation would have yielded recognition as a bachelor's degree, even if the candidate's knowledge and skills had eroded, the refugee candidates' portfolios were assessed compared to a 2004 Norwegian bachelor of engineering. To solve this, one candidate's education was recognized as being equivalent to a Norwegian engineering degree from the same time period as the candidate's degree.

Some candidates had originally given up their profession as previous attempts to obtain recognition had failed, but with the results from the pilot project they had to reconsider this stance and consequently felt a new need for career guidance.

\section{The Costs}

The main cost in the recognition process was the salaries, and the procedure was estimated to require three to seven workdays divided between administrative and academic staff. This was lower than for similar testing in secondary vocational education and less costly than reeducating the candidate. The number of eligible refugees seems to be small, probably less than 200 annually in Norway, but because documentation problems are not registered systematically, the category is hard to trace in statistics.

\section{One Year Later}

One year after the project, I5 candidates were contacted by NOKUT to gain information on their use of the recognition. Five out of these I5 continued their studies in 2004/2005 while 6 expressed a wish to continue as soon as the language requirements for admission were fulfilled. Of the 4 with bachelor'sdegree level recognition, two were studying at the master's level, and one had used the recognition to improve on his employment contract.

One candidate had received no higher education recognition, but had been admitted as a first year student. He found the requirements too demanding and thus withdrew. Those who studied for the final year of a Norwegian bachelor's degree were content because it supplied them with an engineering vocabulary in the Norwegian language, an updating in engineering, and increased ICT skills. Some still worked in irrelevant jobs while they improved their Norwegian-language proficiency or searched for a relevant job, or simply because they had given up on engineering.

NOKUT and the Ministry of Education and Research have advised Norwegian higher education institutions to implement the procedure, and information and application forms are available on NOKUT's website. A number of institutions have started using the procedure, but to avoid a large influx of applicants to the institutions, there has been no official launching event.

\section{THE Future}

Generally, the practice in recognition nowadays is to place more emphasis on getting educational documentation straight from the institutions abroad in order to avoid fraud. This is possible because the lines of communication gradually open up to most countries. There will, however, always be some countries and institutions where verification is impossible for different reasons. Therefore, the need for a special recognition process for refugees cannot be expected to disappear. In most cases an applicant with educational documents can expect a better result through the normal recognition process; hence the recognition procedure for refugees is not considered an easy way out but as a solution for exceptional cases where recognition cannot be based on documents or information from the institution. 